\title{
Approaches Regarding the Functional and Structural Rehabilitation of Historical Monumental Buildings
}

\author{
Gheorghe Croitoru \\ Department of Engineering, Law and Real Estate Evaluation, Faculty of Constructions, Geodesy and Cadaster, Technical \\ University of Moldova, Chisinau, Republic of Moldova \\ Email: gheorghe.croitoru@dmmc.utm.md
}

How to cite this paper: Croitoru, G. (2021) Approaches Regarding the Functional and Structural Rehabilitation of Historical Monumental Buildings. Open Access Library Journal, 8: e7497.

https://doi.org/10.4236/oalib.1107497

Received: May 6, 2021

Accepted: June 7, 2021

Published: June 10, 2021

Copyright $\odot 2021$ by author(s) and Open Access Library Inc.

This work is licensed under the Creative Commons Attribution International License (CC BY 4.0).

http://creativecommons.org/licenses/by/4.0/

(c) (i) Open Access

\begin{abstract}
The aim of the research is to analyze the approaches to the problems of functional and structural rehabilitation of historic monumental buildings. The research examined the possibility of changing the destination of a historic building, which involves both functional rehabilitation (rehabilitation and adaptation of thermal energy, acoustics, water repellent and fire protection) and structural rehabilitation, by replacing or partially modifying the building or, if the structural system allows, complete restoration of its parts; local structural restoration (consolidation); structural modification, by introducing adjacent or incidental construction elements, which together with the existing structure can form another structural system and even change the structural concept using the procedures that can increase strength and stability. As a result of the research, it was established that changing the destination of a building involves both functional rehabilitation, by compartmentalizing the new function, rehabilitation and thermal, energy, acoustic, water repellent adaptation and fire safety of the building undergoing reconversion, and structural rehabilitation. When protecting historical monuments, a series of principles and rules must be observed regarding the owners' interventions, the holders of the administration right, the concessionaires and the tenants.
\end{abstract}

\section{Subject Areas}

Historic Buildings and Restoration Intervention

\section{Keywords}

Historic Buildings, Functional Rehabilitation, Architectural Heritage, Change of Destination, Structural Rehabilitation, Restoration Intervention, Performance Requirements 


\section{Introduction}

The development of constructions reflects the relationship between old and new, between tradition and innovation. The constructions are living testimonies of secular traditions, irreplaceable pages in the history of each nation, appreciable by their antiquity, architectural value or by the historical event they signify. The constructions, which constitute the physical framework of everyday life, often with remarkable architectural potential, must sometimes be adapted to the transformations that have appeared in society, transformations that impose their imprint on them. Once built empirically, based on intuition and experience, which was passed down from generation to generation, through traditions. The constructions have evolved over time in all aspects: architecture, structural design, execution technology.

The monumental constructions represent true works of art and mark important moments in the way of the technical progress and people's civilization.

The object of the research was the existing real estate fund, which is part of the architectural heritage built in the Republic of Moldova, registered in the Register of monuments of the Republic of Moldova and protected by the state.

Previous research has highlighted the problems of preserving historical monuments, which involve reconciling the desire for continuity with preserving the structure and image of a building and the possibilities of use for a new function. The technical problems that may arise during the execution of the works must be analyzed during the rehabilitation and conservation of historic monumental buildings. Every work should be based on the technical archival documentation (if any), the technical expertise reports of the certified technical experts, the analytical and critical reports illustrated with drawings and photographs.

As a result of these researches, it is intended to develop some technical measures, with individual approaches, to rehabilitate old monumental buildings, in terms of solving the problems related to structural rehabilitation, thermal, energy, acoustics, water repellent adaptation and fire safety of buildings undergoing reconversion.

\section{Historical Monuments}

Monuments are objects-a lot of objects-whose preservation and use is in the public interest, for their preservation and use there are artistic, scientific, ethnographic or urban arguments.

The Venice Charter (1964) states that the notion of historical monument includes not only the singular architectural work, but also the urban or rural architectural ensemble, which bears the testimony of a particular civilization, a distinct evolution or a historical event.

The architectural heritage built in the Republic of Moldova includes almost three thousand objects: separate buildings, architectural complexes and built areas (houses and administrative buildings, urban and rural mansions, churches, monasteries, technical and industrial facilities, the historic center of Chisinau, 
etc.), which were registered in the Register of monuments of the Republic of Moldova protected by the state. The preservation of historical monuments has always been favorable through a useful use to society. To strengthen them, the most modern techniques can be applied, the effectiveness of which has been scientifically demonstrated through practical experience. All conservation and restoration work must always be accompanied by accurate documentation, in the form of analytical and critical reports, illustrated with drawings and photographs.

The maintenance of buildings can only be done "in their natural environment" because the problems are technical and they require adequate protection measures.

\section{The Importance of Rehabilitating Old Monumental Buildings}

The existing built fund, being a complex made up of old monumental buildings, expresses the living proof of the past, occupations, history, science, a way of living, which was given to us as an inheritance by our ancestors, to be preserved and transferred to future generations. In this way it can be proved that the past is alive, that it can adapt to modern life and to the new structural and functional requirements.

Changing the destination of a historic building involves both functional rehabilitation (by compartmentalization according to the new function, rehabilitation and adaptation of thermal energy, acoustics, water repellent and fire protection) and structural rehabilitation by replacement or partial modification of the building. Or, if the structural system allows, it includes complete restoration of its parts; local structural restoration (consolidation); structural modification, by introducing adjacent or incidental construction elements, which together with the existing structure can form another structural system and even change the structural concept using the procedures that can increase strength and stability (e.g. insulation of the foundation base for structures located in seismic areas, according to [1]) etc.

By definition, refurbishment or rehabilitation, which costs $25 \%$ - $33 \%$ less than the new construction, involves reconciling the desire for continuity with preserving the building's structure and image and the possibilities to use it corresponding to a new function.

The issue of functional and structural rehabilitation of old historic buildings, in a precarious state, with an advanced degree of physical and moral wear and tear is a contemplative issue for the community of the Republic of Moldova after its independence.

The rehabilitation operations can be:

- Active: allows a self-sustaining existence;

- Passive: does not integrate in the economic circuit;

- Surface: renovation of facades and adjacent rooms;

- In depth: it deals with the facades and the interior of the buildings from the 
rehabilitation area.

The purpose of incorporating the projective measures in the urban documentation is given by the necessity and integration of the existence and enhancement of the architectural heritage in the development of the city. It is important to: attract resources (interest of the administration) and economic amplification of the cultural heritage (common interest of the administration and investors), i.e. to maximize the cost/benefit ratio while respecting the specifics of the heritage and its protection.

A restoration intervention must cover the following activities:

- Preliminary discussions (the beneficiary, the representatives of the local public administration, the responsible for monuments, the representative of the Agency for Inspection and Restoration of Monuments, the designer);

- Expertise: the design specialist of the Monuments Inspection and Restoration Agency, certified technical expert (restoration concepts);

- Preliminary research (archival, archaeological research, building surface, material, color, structure, photographic documentation, surveys, evidence, measurement and drawing operation, etc.);

- Establishing the concept of restoration (based on the results of previous research);

- Tender, offer, financing plan;

- Execution of works;

- Final reception (control of the works according to the restoration concept, report on the executed works, final report on the entire intervention).

The analysis of structural types determines the knowledge of their performances and quality, the assimilation of data and their capitalization in order to prevent degradations through interventions performed over time and as a result of the progress of science and technology (Figure 1) [2].

\section{Legislation and Performance Requirements for Buildings}

Construction performance is a relatively old concept; the level of performance being identified in terms of user requirements in relation to the built space [3]. User requirements are defining elements in the evaluation of the next steps which involve efficiency, optimization, estimating the weight of each requirement in the final evaluation.

The SM SR ISO 6241 standard classifies the user requirements into categories, which includes 14 performance requirements for construction (Figure 2).

The legislative environment, in which the rehabilitation takes place, is characterized by a general legislative framework and specific regulations (urban planning legislation and specific heritage protection legislation).

Law no. 721/1996 applies to constructions of any category and their related installations, regardless of the type of property or destination, as well as to their modernization, modification, transformation, consolidation and repair works $[4]$. 


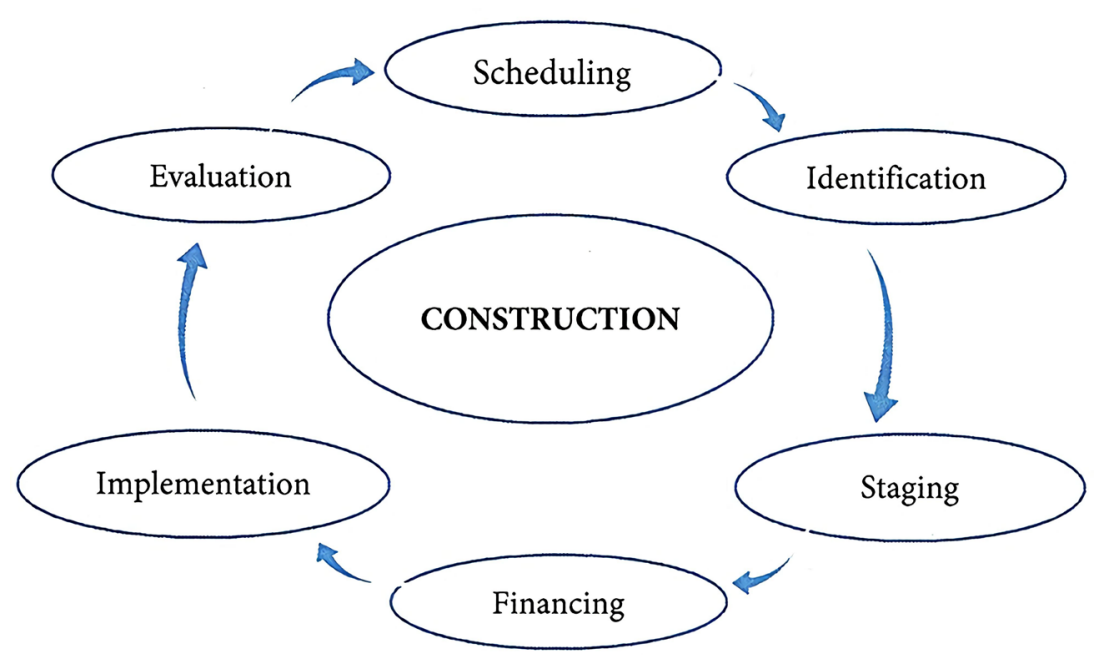

Figure 1. Phases of rehabilitation of a building.

Stability and strength

Fire safety

Safety in use

Tightness of the elements

Hydrothermal comfort

Atmospheric environment

Acoustic comfort

Touch comfort

Anthropodynamic comfort

Visual comfort

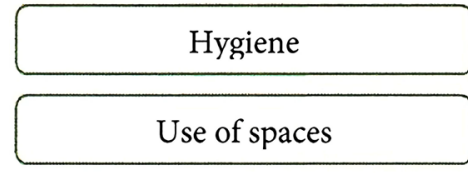

Saving

Durability

Figure 2. Performance requirements for buildings according to [3].

In order to obtain constructions of appropriate quality, it is mandatory to achieve and maintain for the entire duration of the constructions the funda- 
mental requirements, mentioned in the Government Decision no. 913/2016, which applies to construction works and which may influence the essential characteristics of a construction product [5].

The presented legislative framework establishes the minimum conditions necessary to satisfy the quality in constructions for each essential requirement.

The existence of a set of laws does not save the architectural heritage, protection being the only way in which the heritage is valued, but with a precondition: it must be known, evaluated, rehabilitated and preserved.

The refurbishment and rehabilitation of old architectural buildings are a complex action that establishes the way in which a structure is brought back to life, using the procedures that highlight its initial qualities. The transformation of a building must take into account its character; the main interest being focused on the possibility of giving the construction a new chance of life. The intervention must be flexible, so as to provide a balance between preserving the old elements and adapting them to the current standards.

The basic principles in the process of rehabilitation of a construction are presented in Figure 3.

Regarding the protection of historical monuments, a series of principles and rules must be observed regarding the interventions of the owners, the holders of the administration right, the concessionaires and the tenants on the historical monuments, among which the most important are the following:

1) Ensuring the performance of conservation, consolidation and restoration works, as well as any other works, only by natural or legal persons certified for this purpose and the provision in contracts of the conditions and terms of execution contained in the approval of the Ministry of Education, Culture and Research.

2) Observance of all the conditions and terms of execution included in the approval of the Ministry of Education, Culture and Research when they perform themselves the current maintenance works or any other interventions.

3) Allowing, based on the contractual provisions, the execution of interventions on the historical monuments held, in case they are initiated and financed by legal persons authorized under the law.

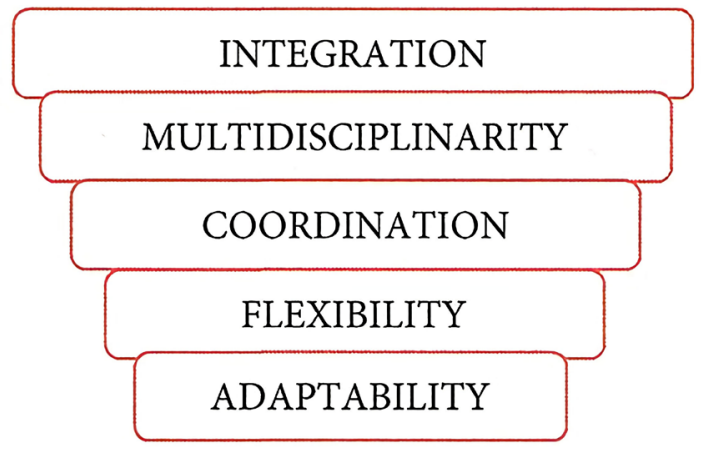

Figure 3. Basic principles in the process of a building rehabilitation. 
4) The interventions may be made only on the basis of and in compliance with the prior opinion issued by the Ministry of Education, Culture and Research. These interventions include:

a) All research, conservation, construction, extension, consolidation, restructuring, landscaping and enhancement works, which change the substance or appearance of the historical monuments-permanent or temporary location of fences, protective constructions, pieces of fixed furniture, billboards, signs, logos or any kind of signs on and in the historical monuments;

b) Changes in the function or destination of the historical monuments, including the temporary changes;

c) Relocation of the historical monuments;

d) Arrangements of access roads, pedestrian and roadways, ancillary utilities, signs, including in the protected areas of the historical monuments.

It is important to note that the basic rule of interventions on monuments, namely that the building permit or demolition permit is issued only on the basis and in accordance with the opinion of the Ministry of Education, Culture and Research. The permit issued without the approval of the institutions authorized by law and without respecting their conditions are null and void [6].

The same conditions are imposed on the interventions carried out on the buildings that are not historical monuments, but which are located in the protected areas of the historical monuments or in protected built areas, according to [7].

\section{Technical Solutions Specific to the Rehabilitation of Monumental Constructions}

\subsection{Structural Rehabilitation}

Over time, different processes of a physical, chemical and biological nature can frequently occur in the structure of a building. They can occur simultaneously. Sometimes they are linked together in a causal succession, having a specific evolution, depending on the physical and chemical properties of materials and various environmental factors. The relationships between the aggressive agents are complex. It is often not possible to establish a main cause for material degradation, humidity being a main generating and favoring factor of their alteration, in close connection with the porosity characteristics of the materials used [8] and [9].

The following categories of interventions are distinguished in the structural rehabilitation of masonry constructions:

1) Repair, completion, reintegration or joining of new construction elements or bodies with a different operating purpose;

2) Consolidation interventions by replacement of structural components and/or consolidation and reintegration of existing structural components:

- an individual consolidation;

- an overall consolidation. 


\subsection{Rehabilitation of Building Waterproofing}

Any construction must be protected against moisture, both in the area of the roof and in the area of foundations, plinths and basements to prevent and avoid, as much as possible, the penetration of water into interior spaces. It must also protect the structural and non-structural components from possible damage, without neglecting its protection against infiltration, due to defects in installations or systems for collecting rainwater.

\subsection{Hydrothermal Rehabilitation of Buildings}

Although the provisions of [10] do not apply to the buildings that are protected according to [11] and that are included in the Register of Local or National Monuments; thermal insulation may be applied in justified cases, to the extent that compliance with certain energy performance requirements would unacceptably alter their historical value or external appearance, high-performance systems.

The current trends in the field, both internationally and nationally, are those of developing high-performance closure and insulation systems that use modern thermal energy rehabilitation measures, based on nanotechnologies and nanomaterials with increased thermal and energy performance.

Thermal rehabilitation works on the building's outer coating or the building elements, which are the components of the outer coating, are intended to reduce the heat loss by increasing the thermal resistance of the closing elements and limiting air infiltration through the glazed elements and joints.

\subsection{Acoustic Rehabilitation of the Buildings}

Building acoustics presents the study of phenomena related to the propagation and reception of acoustic energy in the buildings' functional units in order to ensure sound comfort. The aim is to minimize the passage of sound through the wall, partition or ceiling, in order to create an effective sound insulation.

Some methods of sound insulation are:

- A frequently adopted sound insulation method is to establish a constructive solution based on increasing the weight of the partition by using heavy plasterboard and/or double layers, using the "law of mass";

- Another means of sound insulation is the use of light boards and/or a material that expresses a high absorption capacity;

- Sound insulation by combining air gaps between the plates (cavity) and the weight of the plates to increase the acoustics.

The purpose of sound absorption is the acoustic correction, which involves reducing the sound level in a room, an objective that can be achieved using a material that allows the dissipation of vibrations in the air.

\subsection{Fire Safety in Construction}

The following conditions shall be taken into account when equipping with technical means of fire protection; for the effective fire protection of historic monu- 
mental buildings:

- Control of fire risks, development and spread of fires;

- Compatibility between the means and between the means and the environment;

- Complementarity between the means and forces;

- The optimal ratio between the automated and manual means, correlating the entry and maintenance of safety and operating times;

- Providing for the possibility of supplying the extinguishing systems from mobile means, including the dry pillars;

- The possibility of maintenance and repairs;

- The use only of means approved, notified and technically approved;

- Drawing up the instructions and extinguishing schemes.

\section{Conclusions}

The rehabilitation of historical monuments of cultural heritage in the Republic of Moldova is one of the most important social tasks.

The rehabilitation of the architectural heritage expresses the social-human need to preserve the existing building fund, adapting it, at the same time, to the new requirements of modern civilized life.

The adaptation of a model of rehabilitation of the architectural heritage or of another one must be done with the analysis of the premises and the evaluation of the effects of the situation.

The existence of a package of laws does not save the architectural heritage, protection being the only way in which the heritage is valued, but with a precondition: it must be known, evaluated, rehabilitated and preserved.

Changing the destination of a building involves both functional rehabilitation, by compartmentalizing the new function, rehabilitation, thermal, energy, acoustic and water-repellent adaptation, and fire safety of the building undergoing conversion, and structural rehabilitation.

The knowledge and implementation of the norms and technical regulations regarding the historical monumental buildings lead to a better acquisition of them in their current form and to an application, knowingly, in the practice of expertise and rehabilitation/consolidation of buildings.

The technical solutions specific to the rehabilitation of monumental constructions must be based on the knowledge and application of technical norms and regulations, which lead to a better mastery of them in their current form and to an application, knowingly, in the practice of expertise and rehabilitation/consolidation of the buildings. The technical measures are to be elaborated later, within the project "increasing the value of the architectural heritage of the Republic of Moldova" and which will be the subject of the following publications.

\section{Acknowledgements}

The research was carried out within the project 20.80009.0807.34-increasing the value of the architectural heritage of the Republic of Moldova. 


\section{Conflicts of Interest}

The author declares no conflicts of interest regarding the publication of this paper.

\section{References}

[1] SM EN 1998-5:2011 Eurocod 8: Proiectarea structurilor pentru rezistența la cutremur. Partea 5: Fundații, structuri de susținere şi aspecte geotehnice.

[2] Stanca, S.E. (2018) Contributions Regarding the Functional and Structural Rehabilitation of Old and/or Derelict Buildings. Doctoral Thesis, Cluj Napoca.

[3] SM SR ISO 6241:2010 Performance Standards in Building-Principles for Their Preparation and Factors to Be Considered.

[4] Law No. 721 of 02.02.1996 on Quality in Construction (Published in Official Monitor No. 25 art. Nr: 259).

[5] Government Decision No. 913 of 25.07.2016 on the Approval of the Technical Regulation on the Minimum Requirements for the Marketing of Construction Products (Published in Official Monitor No.247-255/997 of 05.08.2016).

[6] Emodi, T., Pafka, E. and Sim, D. (2010) Guide to Good Practice for the Rehabilitation of Buildings in the Historic Center. Oradea City Hall.

[7] Law No. 163 of 09.07.2010 on the Authorization of the Execution of Construction Works (Published: 03.09.2010 in Official Monitor No. 155-158, art. 549).

[8] Croitoru, G. (2015) Study of the State of Limestone Masonry Materials under the Influence of Aggressive Environments. Materials of the Third International Scientific and Practical Conference, Byelorussia, Minsk, 1-2 December 2015, 100-105.

[9] Croitoru, G. (2014) The Influence of Some Environmental Factors on the Historical Monuments of the Republic of Moldova. Bulletin, Incercom, Chisinau, 88-96.

[10] Law No. 128 of 11.07.2014 on the Energy Performance of Buildings (Published: 10.10.2014 in Official Monitor No. 297-309, art. Nr: 609).

[11] Law No. 1530 of 22.06.1993 on the Protection of Monuments (Published: 30.01.1994 in Official Monitor No. 1 art. 3). 